\title{
Curcumin inhibits LPS-induced EMT through downregulation of NF-кB-Snail signaling in breast cancer cells
}

\author{
TAO HUANG ${ }^{1 *}$, ZHIJUN CHEN $^{1 *}$ and LIPING FANG ${ }^{2}$ \\ ${ }^{1}$ Department of Orthopedic Surgery, Affiliated Hospital of Xi'an Medical College, Xi'an 710077; \\ ${ }^{2}$ Department of Respiratory Medicine, Jinling Hospital of Nanjing, Nanjing 210001, P.R. China
}

Received June 15, 2012; Accepted September 3, 2012

DOI: 10.3892/or.2012.2080

\begin{abstract}
Epithelial-mesenchymal transition (EMT) is considered a critical event in cancer cell invasion and metastasis. Emerging evidence has shown that curcumin may prevent or delay the progression of cancer, an effect that may be partially due to its ability to disrupt EMT, yet this has not yet been demonstrated. In this study, we used lipopolysaccharide (LPS) to trigger EMT in MCF-7 and MDA-MB-231 breast cancer cell lines and showed that curcumin inhibited LPS-induced morphological changes, decreased the expression of LPS-induced markers of EMT such as vimentin, and increased the expression of E-cadherin, resulting in the inhibition of in vitro cell motility and invasiveness. We discovered that these actions were mediated through the inactivation of $\mathrm{NF}-\kappa \mathrm{B}-$ Snail signaling pathways. Our results indicate that curcumin plays an important role in the inhibition of LPS-induced EMT in breast cancer cells through the downregulation of $\mathrm{NF}-\kappa \mathrm{B}-\mathrm{Snail}$ activity. These data provide a new perspective of the anti-invasive mechanism of curcumin, indicating that the effect is partly due to its ability to attack the EMT process.
\end{abstract}

\section{Introduction}

Breast cancer is the leading cancer in women, affecting millions worldwide. In metropolitan cities it ranks as the most common cancer (1). The prognosis for patients with advancedstage breast cancer is related to the degree of aggressive metastasis. Once breast cancer has spread, there are limited effective treatment options (2). Therefore, there is an urgent

Correspondence to: Dr Liping Fang, Department of Respiratory Medicine, Jinling Hospital of Nanjing, 305 East Zhongshan Road, Nanjing, Jiangsu 210001, P.R. China

E-mail: xf4652@yahoo.com.cn

*Contributed equally

Key words: curcumin, breast cancer, $\mathrm{NF}-\kappa \mathrm{B}$, invasion, epithelialmesenchymal transition need to understand the mechanisms involved in the progression of cancer. The process of cancer metastasis appears to be regulated by a variety of gene products, since the precise mechanisms of dissemination are not well understood.

One important concept of epithelial-mesenchymal transition (EMT), which has been recognized for several decades as a fundamental process of embryogenesis, is currently considered a pivotal event in the initial step of the metastatic cascade that allows cells to acquire migratory, invasive and stem-like properties (3). During EMT of cancer cells in situ, epithelial cell layers lose polarity together with cell-to-cell contacts and then undergo a dramatic remodeling of the cytoskeleton. The expression of proteins that promote cell-to-cell contact, such as E-cadherin and $\gamma$-catenin, may be lost, and the cells may acquire mesenchymal markers such as vimentin, fibronectin, $\mathrm{N}$-cadherin, and the metalloproteinases MMP-2 and MMP-9, resulting in an enhanced ability for cell migration and invasion (4). Once migrating to a suitable site, tumor cells re-express E-cadherin and other epithelial markers through a process that is often referred to as mesenchymal-epithelial transition (MET) (5). Induction of EMT is driven through the complex interplay between cancer cells and the tumor environment. The mechanisms include the activation of several transcriptional repressors, notably Snail, Slug and Twist, through multiple cellular signaling pathways such as NF-kB, Wnt and Hedgehog (6-10). Thus, reversing or blocking the EMT process is a promising therapeutic strategy for limiting the spread of cancer.

Dietary chemopreventive agents have received much attention in the area of cancer research. It is estimated that one third of all cancers may be prevented by diet modification, maintenance of optimum body weight and regular physical activity $(11,12)$. Among several dietary chemopreventive agents, curcumin has gained considerable interest. Curcumin, an active component of the spice turmeric (Curcuma longa), has been shown to inhibit carcinogen activation, induce carcinogen-detoxifying and antioxidant enzymes, modulate cell survival and apoptosis, inhibit angiogenesis and to evoke anti-invasive and anti-metastatic effects (13). The antitumor mechanisms of curcumin involve the NF-kB, PI3K/Akt, MAPK, Wnt and Notch signaling pathways $(14,15)$.

Notably, it has been known that curcumin inhibits cancer cell invasion by suppressing both constitutive and inducible NF-kB activation (16). The NF-kB signaling pathway is critically involved in the acquisition of Snail-mediated EMT (17). 
Moreover, during the progression to metastatic competence, carcinoma cells have been described to enter into an EMT program, allowing them to acquire features of mesenchymal-like cells that may significantly endow invasiveness (18). Whether the anti-invasive effects of curcumin are a result of its ability to attack EMT has not yet been demonstrated in breast cancer cells. Based on a previous study showing that lipopolysaccharide (LPS) induces EMT in cancer cells (19), we used LPS to induce EMT in the following experiments. The aim of this study was to investigate the potential of curcumin to inhibit LPS-triggered EMT in breast cancer cells. We suggest that curcumin may inhibit LPS-induced EMT and that this effect is accompanied by the inhibition of the NF-kB-Snail signaling pathway.

\section{Materials and methods}

Cell cultures and treatments. MDA-MB-231 and MCF-7 human breast cancer cell lines (obtained from the American Tissue Type Collection, USA) were maintained in Dulbecco's modified Eagle's medium (DMEM; Gibco, USA) supplemented with penicillin $(100 \mathrm{U} / \mathrm{ml})$, streptomycin $(100 \mu \mathrm{g} / \mathrm{ml}), 0.1 \mathrm{mM}$ non-essential amino acids, $0.2 \mathrm{mM}$ glutamine, $1 \mathrm{mM}$ pyruvate, and $10 \%$ heat-inactivated fetal bovine serum (FBS) and incubated in a $5 \% \mathrm{CO}_{2}$ humidified atmosphere at $37^{\circ} \mathrm{C}$. Cells were grown to $80 \%$ confluency prior to treatment. The antibodies against $\mathrm{NF}-\kappa \mathrm{B}$ p65 subunit, Snail, E-cadherin, vimentin and $\beta$-actin were purchased from Santa Cruz Biotechnology (Santa Cruz, CA, USA). Matrigel, LPS, curcumin, NF- $\kappa \mathrm{B}$ inhibitor PDTC were purchased from Sigma (Beijing, China).

Proliferation assay. Cell proliferation was determined by the 3-(4,5-dimethylthiazol-2-yl)-2,5-diphenyltetrazolium bromide (MTT, Sigma) uptake method. After the cells were seeded $\left(5 \times 10^{3} /\right.$ well $)$ in $200 \mu \mathrm{l}$ of DMEM medium into 96 -well plates and cultured overnight, curcumin $(0-70 \mu \mathrm{M})$ was added to the cells and further cultured for $24 \mathrm{~h}$. Then, MTT reagent $(5 \mathrm{mg} / \mathrm{ml})$ was added and incubation was continued for an additional $4 \mathrm{~h}$. The reaction was terminated with $150 \mu \mathrm{l}$ dimethyl sulfoxide (DMSO, Sigma) per well. Absorbance values were determined using an MRX Revelation 96-well multiscanner (Dynex Technologies, Chantilly, VA, USA). The cells cultured in DMEM served as the control group. The cell viability index was calculated according to the following formula: Experimental OD value/Control OD value. The experiments were repeated 3 times.

Transmission electron microscopy. The cells treated or untreated with LPS and/or curcumin were harvested and rinsed with PBS. Cells were fixed for $30 \mathrm{~min}$ in $4 \%$ paraformaldehyde and $1 \%$ glutaraldehyde in $0.1 \mathrm{M}$ phosphate buffer $(\mathrm{pH}$ 7.4) (PB), rinsed in $\mathrm{PB}$, and post-fixed in $1 \%$ osmium tetraoxide for $30 \mathrm{~min}$. After washing in $\mathrm{PB}$, cells were progressively dehydrated in a $10 \%$ graded series of $50-100 \%$ ethanol and then cleared in QY-1 (Nissin EM, Tokyo Japan). Cells were embedded in Epon 812 resin, and thin sections $(70 \mathrm{~nm}$ thickness) were stained with uranyl acetate and lead citrate, and then examined by transmission electron microscopy.

Cell invasion assay. Cell invasion assay was performed and evaluated as recently described in detail by employing Boyden chambers equipped with $8 \mu \mathrm{m}$ porosity polyvinylpyrrolidonefree polycarbonate filters that were coated with $50 \mu \mathrm{g} / \mathrm{ml}$ of Matrigel solution (20). The cells were first seeded in 12-well plates at a concentration of $2.5 \times 10^{5} /$ well and were cultured for $48 \mathrm{~h}$ following treatment with LPS $(5 \mu \mathrm{g} / \mathrm{ml})$. For the co-treatment experiment, $20 \mu \mathrm{M}$ curcumin was added to the cell cultures $1 \mathrm{~h}$ before the addition of LPS. Normal culture medium was added at the bottom chamber to induce the cancer cell lines. Cells which were pretreated were seeded in the top chamber. The Matrigel invasion chamber was incubated for $24 \mathrm{~h}$ in a humidified tissue culture incubator. After $24 \mathrm{~h}$, the non-invasive cells were removed from the upper surface of the separating membrane by gentle scrubbing with a cotton swab, and the invading cells were fixed in $100 \%$ methanol and stained with $0.1 \%$ crystal violet solution. They were then counted under a microscope at a magnification of $\mathrm{x} 200$.

$R T-P C R$. Total RNA from MDA-MB-231 and MCF-7 cells was isolated using TRIzol reagent (Gibco-BRL), and the quantities were determined spectrophotometrically. First-strand cDNA was synthesized from $2 \mu \mathrm{g}$ of total RNA using the RevertAid kit (MBI Fermentas, USA). Sequences of the PCR primers were: E-caderin (502 bp) forward 5'-CGC ATT GCC ACA TAC A-3' and reverse 5'-CGT TAG CCT CGT TCT CA-3'; Vimentin (690 bp) forward 5'-CGC TTC GCC AAC TAC AT-3' and reverse 5'-AGG GCA TCC ACT TCACAG-3; $\beta$-actin (179 bp) forward 5'-ATC GTG CGT GAC ATT AAG GAG AAG-3' and reverse 5'-AGG AAG GAA GGC TGG AAG AGT G-3'. The PCR conditions included an initial cDNA synthesis reaction at $42^{\circ} \mathrm{C}$ for $1 \mathrm{~h}$ using the RevertAid kit, followed by a denaturation step for $5 \mathrm{~min}$ at $95^{\circ} \mathrm{C}$ and 22 cycles of $30 \mathrm{sec}$ at $95^{\circ} \mathrm{C}, 30 \mathrm{sec}$ at $57^{\circ} \mathrm{C}$, and $30 \mathrm{sec}$ at $73^{\circ} \mathrm{C}$. After the last cycle, a final extension was performed at $73^{\circ} \mathrm{C}$ for $10 \mathrm{~min}$. The housekeeping gene $\beta$-actin was used as an internal control.

Preparation of nuclear extracts. Breast cells from the control and experimental groups were incubated on ice for $30 \mathrm{~min}$, followed by the preparation of nuclear extracts using a nuclear extract kit (Pierce, IL, USA) according to the manufacturer's instructions. Samples were washed with ice-cold PBS, scraped, and collected by centrifugation at $500 \mathrm{x}$ g for $5 \mathrm{~min}$. The pellets were suspended in $500 \mu 1$ hypotonic buffer, incubated on ice for $20 \mathrm{~min}$, and centrifuged at $15,000 \mathrm{x} \mathrm{g}$ for $30 \mathrm{sec}$ at $4^{\circ} \mathrm{C}$. The resulting nuclear pellet was suspended in $50 \mu \mathrm{l}$ of complete lysis buffer and incubated on ice for $30 \mathrm{~min}$ with frequent mixing. Finally, the suspension was centrifuged at $16,000 \mathrm{x} \mathrm{g}$ for $30 \mathrm{~min}$ at $4^{\circ} \mathrm{C}$, and the supernatant (nuclear extract) was collected and stored at $-70^{\circ} \mathrm{C}$ until use. Protein concentration was measured by the Bradford assay with BSA as the standard.

Western blotting. Briefly, $5 \times 10^{5}$ cells were incubated on ice for $30 \mathrm{~min}$ in $0.5 \mathrm{ml}$ of ice-cold whole-cell lysate buffer. Debris was removed by centrifugation. The protein content of the cell was determined, and the cellular lysates were separated by 10\% SDS-PAGE and electro-transferred onto nitrocellulose membranes. After being blocked with 5\% non-fat milk in TBST, the membranes were incubated with primary antibodies at $4^{\circ} \mathrm{C}$ overnight, followed by 1:2,000 horseradish peroxidase (HRP)conjugated secondary antibody (Santa Cruz Biotechnology) for 

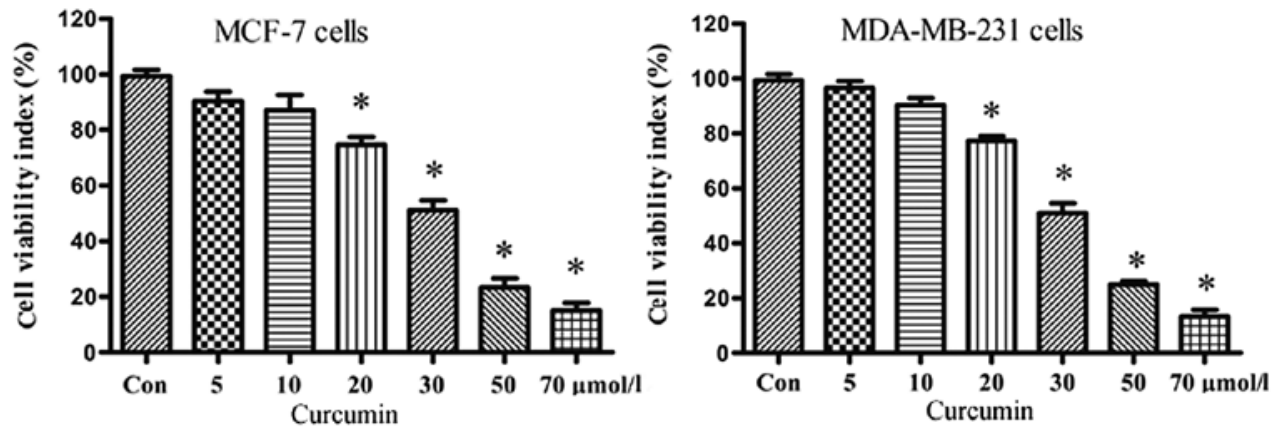

Figure 1. Anti-proliferative effect of curcumin (0-70 $\mu \mathrm{mol} / \mathrm{l})$ after $24 \mathrm{~h}$ in MCF-7 and MDA-MB-231 cells. Results are representative of 3 independent experiments. "P<0.05 vs. the untreated group. Con, Control.

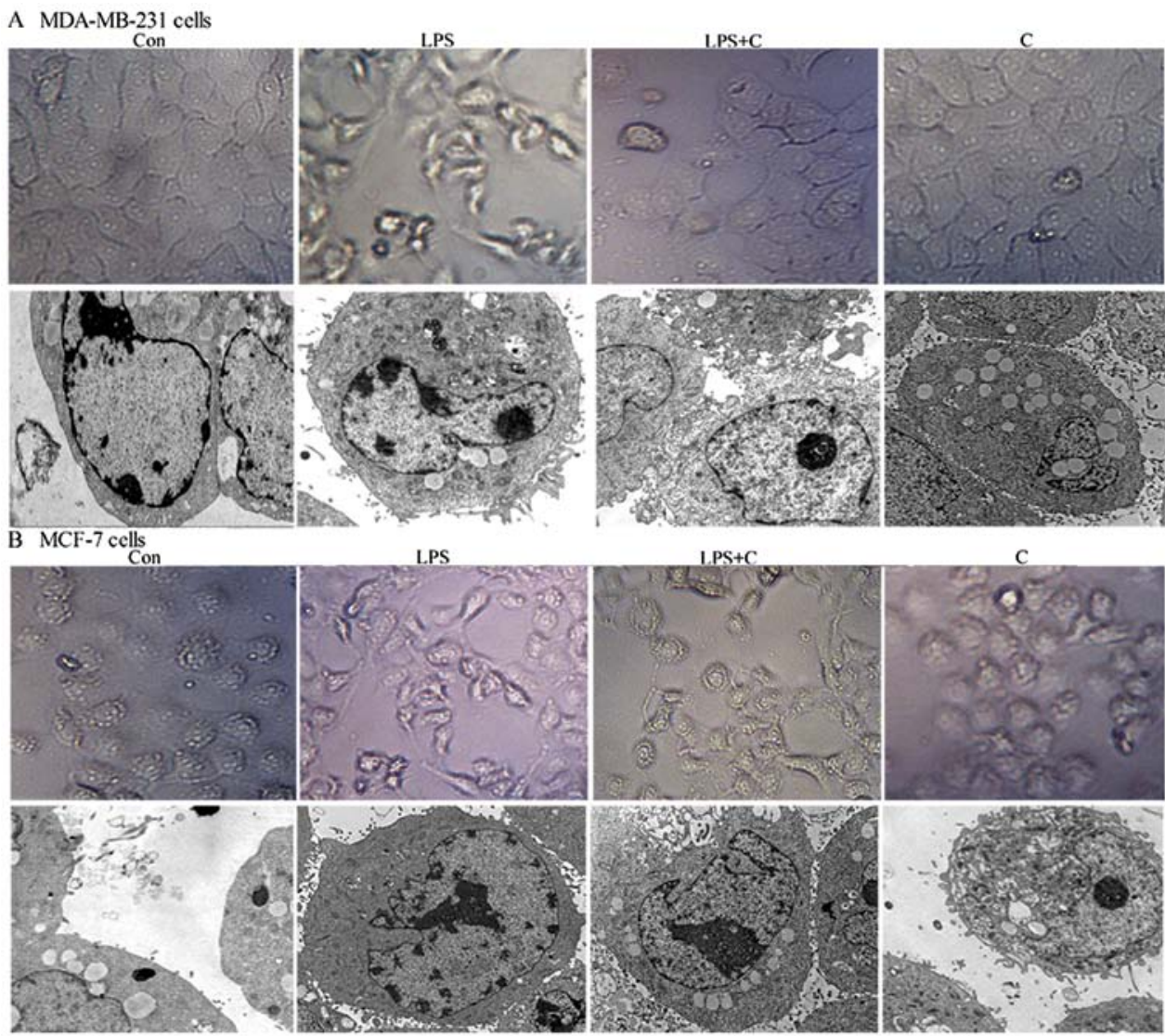

Figure 2. Curcumin inhibited LPS-induced cell morphological changes characteristic of EMT in MCF-7 and MDA-MB-231 cells. Cells were incubated with either LPS $(5 \mu \mathrm{g} / \mathrm{ml})$ or LPS plus curcumin $(20 \mu \mathrm{mol} / \mathrm{l})$. After $48 \mathrm{~h}$, cellular EMT morphological changes were examined by optical (x400) and transmission electron microscopy (x6,000-10,000) in MDA-MB-231 (A) and MCF-7 cells (B): optical microscopy showed cells acquired a spindle-shaped and fibroblast-like phenotype; transmission electron microscopy showed extracellular microvilli were increased in a number of cells. Results are representative of 3 independent experiments. Con, control group; LPS+C, LPS + curcumin group; C, curcumin group.

$2 \mathrm{~h}$. Immunoreactive bands were visualized using an enhanced chemiluminescence kit (Amersham Pharmacia Biotech, Piscataway, NJ, USA). Western blot signals were quantitated by densitometric analysis using Total Lab Nonlinear Dynamic Image analysis software (Nonlinear, USA).

Statistical analysis. Each experiment was performed at least 3 times. Data are indicated as mean values \pm standard deviation and differences were evaluated using a Student's t-test. A probability value $<0.05$ was considered to indicate a statistically significant result.

\section{Results}

Effect of curcumin on the growth of breast cancer cells in vitro. We initially investigated the effect of curcumin on the proliferation of MCF-7 and MDA-MB-231 cells. Both breast cancer cell lines were treated for $24 \mathrm{~h}$ with graded concentrations of curcumin (0-70 $\mu \mathrm{mol} / \mathrm{l})$ and cell viability was measured by MTT assay. The resulting growth curves demonstrated that cell proliferation was inhibited in a dose-dependent manner by curcumin (Fig. 1), with pronounced inhibition at doses $\geq 30 \mu \mathrm{mol} / 1$. These results suggest that curcumin exhibits 

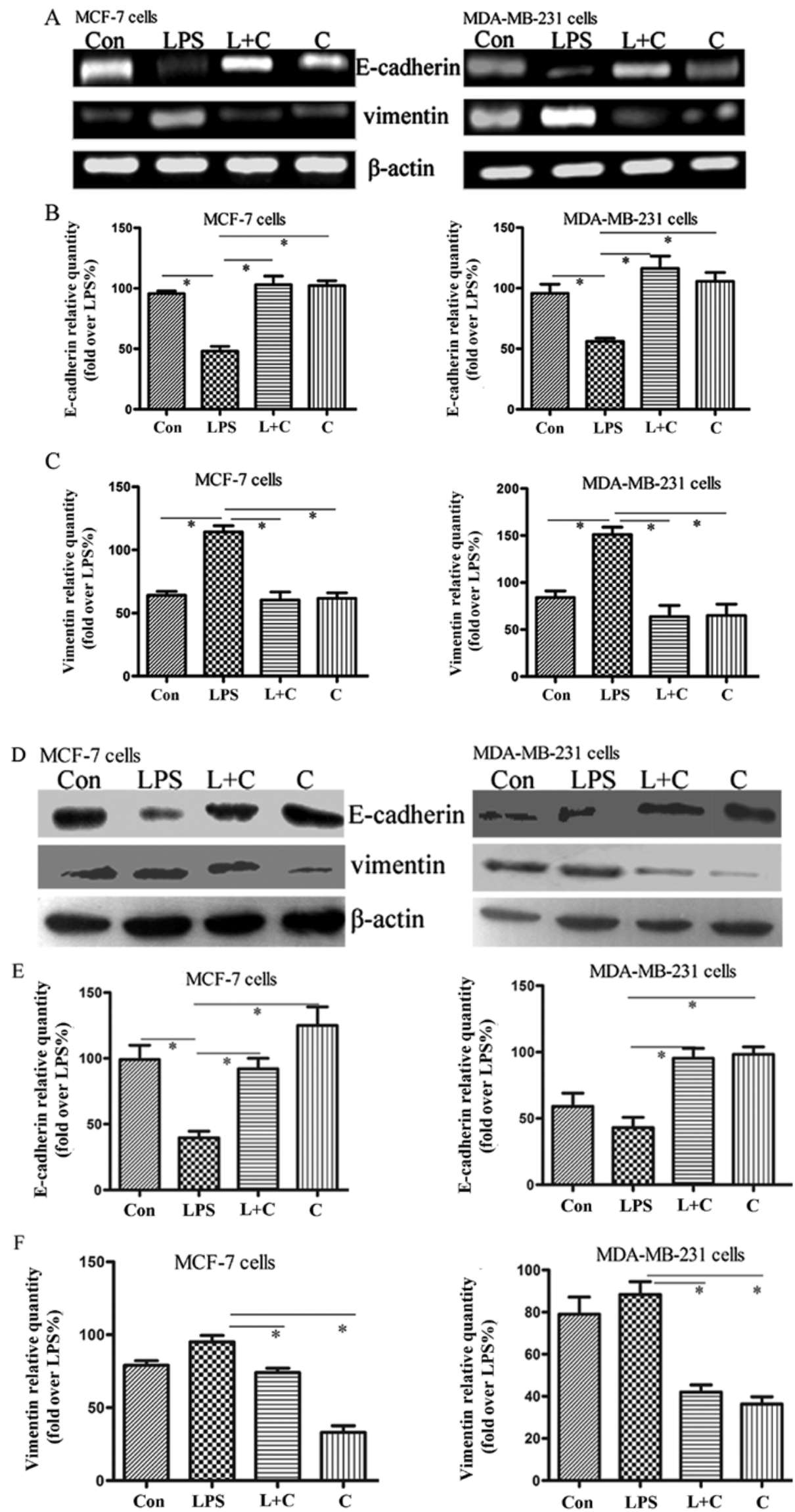

Figure 3. Curcumin prevented the LPS-induced decrease in the expression of E-cadherin mRNA and protein and LPS-induced increase in the expression of vimentin mRNA and protein. (A) The mRNA expression levels of E-cadherin and vimentin in MCF-7 and MDA-MB-231 cells were determined by RT-PCR. (B and C) Quantification of mRNA by real-time PCR. (D) The protein expression of E-cadherin and vimentin in MCF-7 and MDA-MB-231 cells was determined using western blot analysis. (E and F) Quantification of western blot data. Data from at least 3 independent experiments with duplicate determinations are expressed as the means \pm SEM. Con, control group; LPS $+C$, LPS + curcumin group; $C$, curcumin group. ${ }^{*} \mathrm{P}<0.05$ was considered to indicate a statistically significant result. 


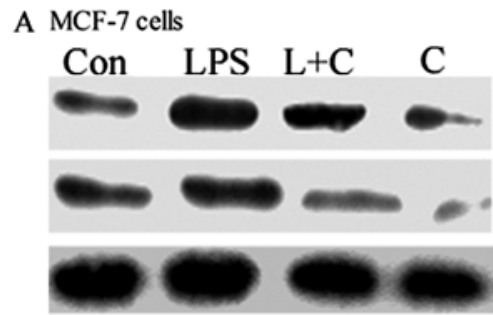

B

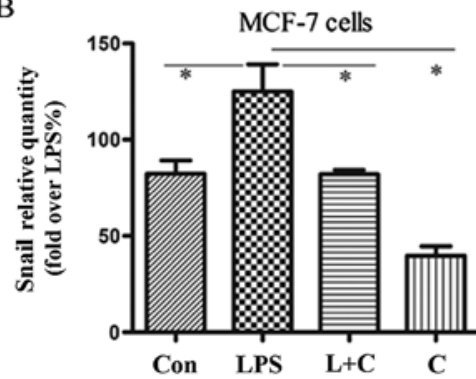

$\mathrm{C}$

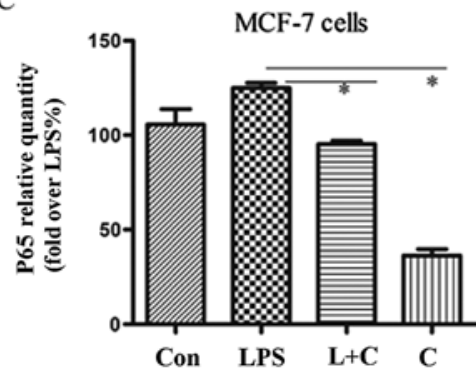

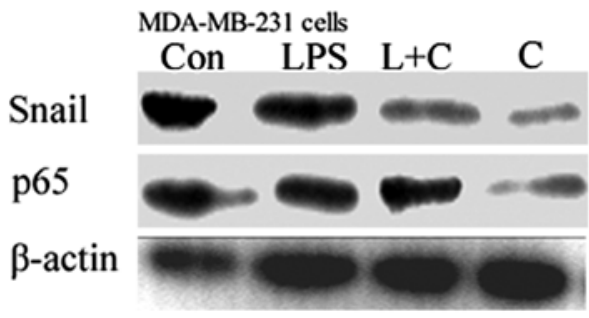
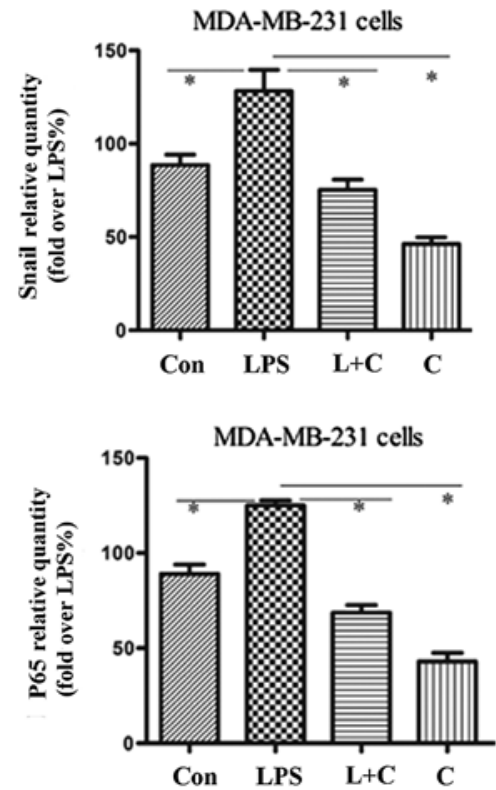

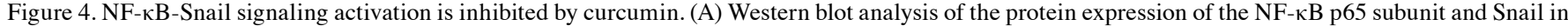
MCF-7 and MDA-MB-231 cells after treatment for $24 \mathrm{~h}$ with cell control, (lane 1); LPS, (lane 2); LPS + curcumin, (lane 3); and curcumin, (lane 4). (B and C) Quantification of the western blot data. $\beta$-actin protein was used as an internal control. Densiometric measurement of NF- $\mathrm{kB}$ p65 and Snail protein levels was normalized to an internal control and expressed as a relative value. ${ }^{*} \mathrm{P}<0.05$ was considered to indicate a statistically significant result.

potent growth inhibition. In light of further experiments, we considered $20 \mu \mathrm{mol} / 1$ curcumin a suitable dose.

Curcumin inhibits LPS-induced cell morphological changes of EMT in breast cancer cells. Previous studies suggest that LPS $(5 \mu \mathrm{g} / \mathrm{ml})$ as an independent factor may trigger the EMT process (19). To verify this phenomenon and to determine whether curcumin $(20 \mu \mathrm{mol} / \mathrm{l})$ inhibits LPS-induced EMT, we used optical and transmission electron microscopy to investigate changes in the morphology of MCF-7 and MDA-MB-231 human breast cancer cells exposed to LPS in the presence or absence of curcumin. Cells were treated with LPS for $48 \mathrm{~h}$. As shown in Fig. 2, both cell types underwent typical EMT morphological changes in response to LPS. There was a loss of cell-to-cell contact, resulting in scattered clusters of cells. Optical microscopy showed that cells acquired a spindleshaped and fibroblast-like phenotype; transmission electron microscopy showed the appearance of dense core particles in the cell cytoplasm, a wire-like structure was noted in the nucleus, and extracellular microvilli were increased in a number of cells. It was subsequently determined that curcumin inhibited these LPS-induced phenomena. A mesenchymal phenotype was much less evident in cells co-treated with PLS and curcumin compared with the cells treated with LPS alone (Fig. 2). These results indicate that curcumin inhibits LPS-induced EMT.
Curcumin inhibits the expression of markers of EMT in breast cancer cells. To further confirm the effects of curcumin on LPS-induced EMT, we sequentially analyzed the expression of two EMT markers, E-cadherin and vimentin. Protein expression was measured by western blotting, and mRNA expression was measured using semi-quantitative RT-PCR analysis. Semiquantitative PCR (Fig. 3A-C) indicated that mRNA levels of vimentin and E-cadherin were significantly increased and suppressed, respectively, by LPS treatment. Western blotting (Fig. 3D-F) showed that the expression of E-cadherin protein was significantly downregulated in the LPS group compared to the control, whereas vimentin protein expression was substantially increased $(\mathrm{P}<0.05)$. Notably, curcumin reversed LPS-induced EMT, causing re-induction of E-cadherin and inhibition of vimentin expression (Fig. 3). These results further suggest that curcumin has inhibitory effects on cellular EMT.

$N F-\kappa B$-Snail signaling is required to decrease $E$-cadherin and increase vimentin expression. As shown in previous studies, curcumin may inhibit cancer cell invasion by suppressing $\mathrm{NF}-\kappa \mathrm{B}$ activation (16). Moreover, the $\mathrm{NF}-\kappa \mathrm{B}$ signaling pathway is critically involved in the acquisition of EMT mediated by Snail, the direct downstream transcription factor (17). To explore whether the above effect of curcumin is associated with the inhibition of $\mathrm{NF}-\kappa \mathrm{B}-$ Snail activation, the expression level of the NF- $\mathrm{B}$ p65 subunit, which represents the active form 
A
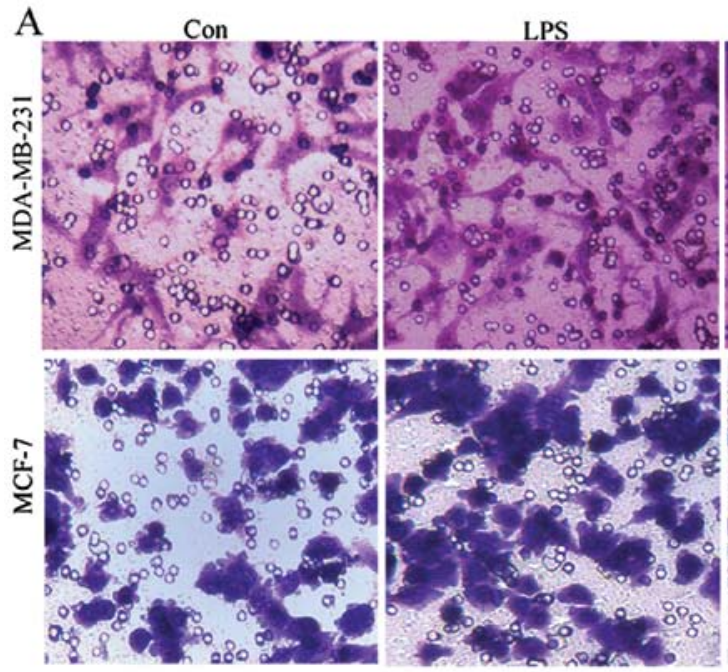

B

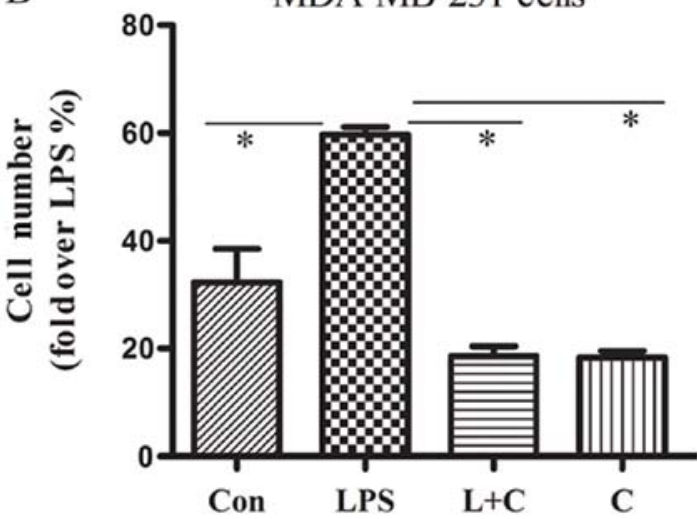

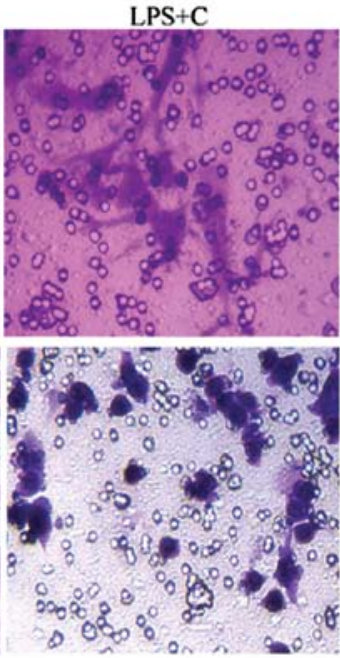
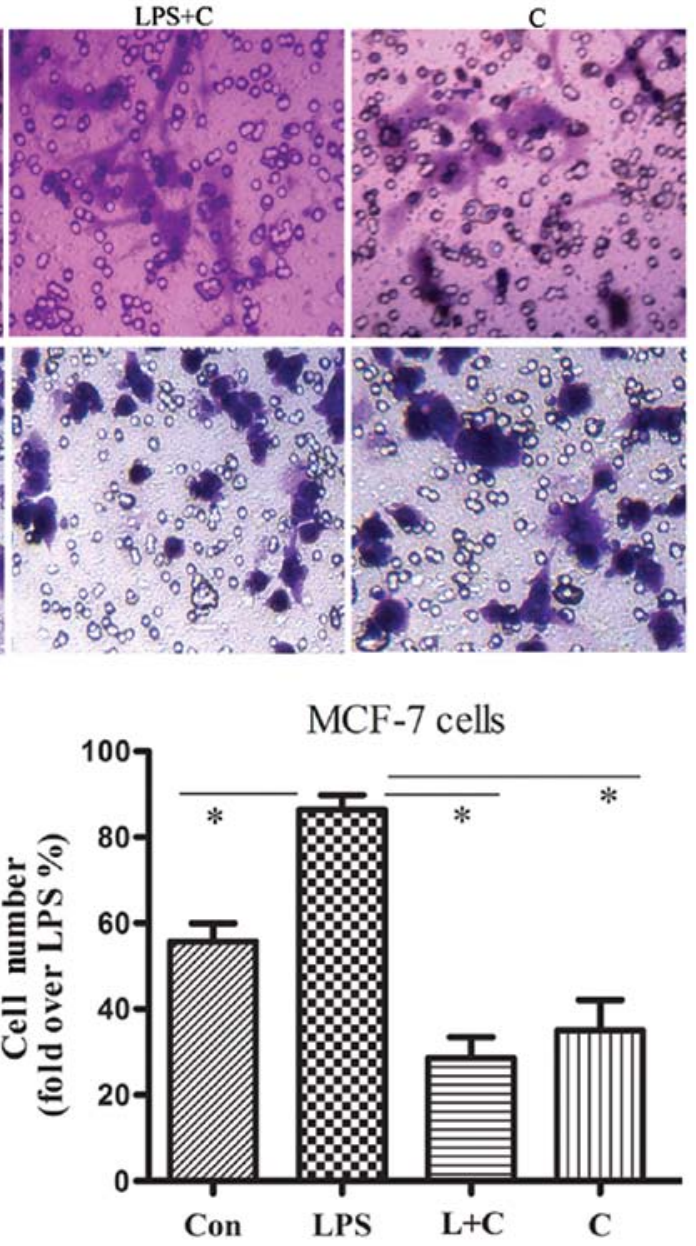

Figure 5. Cell invasion assay in MCF-7 and MDA-MB-231 cells. LPS significantly stimulated cell invasion, an effect completely blocked by curcumin. (A) images displaying the bottom side of the filter inserts with cells that migrated through the filter pores. (B) Columns in the graph represent the analysis of the cell count. ${ }^{*} \mathrm{P}<0.05$ was considered statistically significant.

of $\mathrm{NF}-\kappa \mathrm{B}$, and Snail protein were measured in breast cancer cells by western blot analysis. Our results demonstrated that LPS promoted the expression of NF- $\mathrm{B}$ p 65 and Snail protein, accompanied by a decreased expression of E-cadherin and an increased expression of vimentin, and this effect was blocked by curcumin (Fig. 4). We also showed that NF- $\mathrm{BB}$ inhibitor PDTC reversed LPS-induced EMT, accompanied by the inhibition of Snail and vimentin expression and an increase in the expression of E-cadherin. These results indicate that NF- $\mathrm{BB}-$ Snail plays a critical role in the EMT process.

Curcumin inhibits invasion of breast cancer cells. EMT is associated with enhanced cellular progression. Our observation that curcumin inhibits the EMT process prompted us to examine whether curcumin affects the invasion of breast cancer cells stimulated with LPS. The motile phenotypes of cells treated with LPS and the combination of LPS plus curcumin were evaluated by invasion assay. After treatment with LPS alone, the number of invasive cells increased significantly compared to the untreated cells. The number of invasive cells was significantly reduced in cells co-treated with LPS and curcumin (Fig. 5). These results suggest that curcumin blocks the effect of LPS to increase the invasiveness of human breast cancer cells.

\section{Discussion}

EMT has been proposed as a key process in embryonic development and cancer progression, by which epithelial cells acquire mesenchymal, fibroblast-like phenotypes with reduced cell-tocell adhesion, loss of cell polarity, with increased migration and invasiveness (21). EMT facilitates the migration of tumor cells from their site of origin and dissemination to distant tissues through the activation of a specific genetic program (18). This process is triggered by autocrine and paracrine signals. Thus, agents that may block or reverse this process may offer a promising therapeutic strategy to limit cancer diffusion.

Previous studies have implicated a role for LPS in mediating EMT in breast cancer cells by modifying $\mathrm{NF}-\kappa \mathrm{B}$ signaling (19). In this study, we showed that MDA-MB-231 and MCF-7 cells may be induced by LPS to undergo representative EMT, characterized by the acquisition of mesenchymal phenotype, the disappearance of E-cadherin, and the appearance of vimentin. Treatment with curcumin inhibited LPS-induced EMT. Curcumin not only restored an epithelial phenotype in mesenchymal cells, but also blocked the expression of LPS-induced EMT markers. We further showed that NF- $\mathrm{BB}-$ Snail signaling was required for LPS-induced EMT in MDA-MB-231 and MCF-7 human breast cancer cells. These 
findings extend our understanding of the mechanism by which curcumin may act to inhibit cancer cell invasiveness.

Curcumin is an antioxidant polyphenol derived from several curcuma species, commonly known as turmeric (Curcuma longa), which has been shown to inhibit carcinogen activation and angiogenesis, modulate cell survival and apoptosis, with anti-invasive and anti-metastatic effects on breast, lung, colon and prostate cancer (15). Bachmeier et al demonstrated that curcumin inhibits cancer metastases by downregulating the inflammatory cytokines CXCL-1 and CXCL-2 through modifying NF- $\kappa \mathrm{B}$ signaling in breast cancer cells (22). It was also reported that curcumin inhibits integrin ( $\alpha 6 \beta 4$ )-dependent breast cancer cell motility and invasion via PI3K/AKT signaling (23). Lin et al (24) also reported that curcumin inhibits the migration and invasion of human A549 lung cancer cells through the inhibition of MMP-2, MMP-9 and VEGF. Unfortunately, these strong anti-metastatic effects have not been linked to the EMT process. Most importantly, to the best of our knowledge, our study is the first to demonstrate that the anti-metastatic effects of curcumin are associated with the EMT process in cultured breast cancer cells. Our results offer a new perspective on the role of curcumin in preventing the progression of cancer.

Our data also demonstrated that the mechanism of action for curcumin may involve the suppression of NF- $\mathrm{NB}-\mathrm{Snail}$ signaling. $\mathrm{NF}-\kappa \mathrm{B}$ is a structurally conserved family of dimeric transcription factors, which contain sequences mediating dimerization, DNA binding, nuclear localization, and interaction with inhibitory $\mathrm{I} \kappa \mathrm{B}$ proteins $(25,26)$. NF- $\kappa \mathrm{B}$ plays pivotal roles in both promoting and maintaining an invasive phenotype (27). Moreover, numerous sources of evidence have identified NF- $\mathrm{NB}$ as an essential central mediator of EMT. For example, studies showed that Snail transcription, well established as playing critical roles in EMT, is directly activated by $N F-\kappa B(17)$. NF- $\kappa B$ was identified as the upstream regulator of Snail expression during EMT in human mammary epithelial MCF10A cells. Specifically, the induction of Snail mRNA during EMT may be reversed by the inhibition of $\mathrm{NF}-\kappa \mathrm{B}$ signaling (28). Our results support previous findings that $\mathrm{NF}-\kappa \mathrm{B}$ is the upstream regulator of Snail and indirectly mediates EMT and provides the basis for a new theory for the inhibition of tumor progression by curcumin.

E-cadherin plays a major role in cell-to-cell adhesion of epithelial cells and acts as a metastatic suppressor in epithelial carcinomas. Loss of E-cadherin is significantly associated with advanced diseases (29). Vimentin is the major intermediate filament protein found in mesenchymal cells. Vimentin expression has often been noted in the end stage progression in EMT, representing the completely dedifferentiated state in tumor cells that are highly proliferative and invasive (30). These two important markers of EMT are directly regulated by Snail $(31,32)$. Many preventive agents have been verified to effectively inhibit EMT through the inhibition of Snail transcription factors. Sulforaphane was shown to decrease the self-renewal capacity of pancreatic cancer stem cells by inhibiting the EMT process. The combination of quercetin with sulforaphane was found to have further synergistic effects on Snail-induced downregulated and upregulated expression of E-cadherin and vimentin, respectively (33). Vergara et al (34) reported that resveratrol inhibited epidermal growth factor-induced EMT by inhibiting the expression of vimentin and Slug in MCF-7 cells, and Chen et al (19) also reported that resveratrol inhibits LPS-induced EMT in a mouse melanoma model. In the present study curcumin inhibited the expression of Snail and downregulated or upregulated, respectively, the expression of the EMT markers E-cadherin and vimentin, and retarded cancer cell invasion. Although these agents were primarily verified as effective in retarding EMT, further study will be required to clarify the regulatory mechanism in vivo.

Taken together, these results suggest that the ability of curcumin to inhibit tumor invasion is associated with the EMT process, possibly by inhibiting the activation of NF- $\kappa \mathrm{B}-$ Snail signaling and regulating the expression of the important downstream EMT markers E-cadherin and vimentin. This result provides new mechanistic bases for the therapeutic application of curcumin in breast cancer patients.

\section{Acknowledgements}

This study was funded by the Foundation of the General Hospital of Nanjing Military Region, China.

\section{References}

1. Beiki O, Hall P, Ekbom A and Moradi T: Breast cancer incidence and case fatality among 4.7 million women in relation to social and ethnic background: a population-based cohort study. Breast Cancer Res 14: 1-13, 2012

2. Malfettone A, Saponaro C, Paradiso A, Simone G and Mangia A: Peritumoral vascular invasion and NHERF1 expression define an immunophenotype of grade 2 invasive breast cancer associated with poor prognosis. BMC Cancer 12: 106-117, 2012.

3. Cowin P and Welch DR: Breast cancer progression: controversies and consensus in the molecular mechanisms of metastasis and EMT. J Mammary Gland Biol Neoplasia 12: 99-102, 2007.

4. Moreno-Bueno G, Portillo F and Cano A: Transcriptional regulation of cell polarity in EMT and cancer. Oncogene 27: 6958-6969, 2008.

5. Creighton CJ, Chang JC and Rosen JM: Epithelial-mesenchymal transition (EMT) in tumor-initiating cells and its clinical implications in breast cancer. J Mammary Gland Biol Neoplasia 15: 253-260, 2010.

6. Vuoriluoto K, Haugen $\mathrm{H}$ and Kiviluoto S: Vimentin regulates EMT induction by Slug and oncogenic H-Ras and migration by governing Axl expression in breast cancer. Oncogene 30: 1436-1448, 2011.

7. Hardy KM, Booth BW, Hendrix MJ, Salomon DS and Strizzi L: ErbB/EGF signaling and EMT in mammary development and breast cancer. J Mammary Gland Biol Neoplasia 15: 191-199, 2010.

8. Vincan E and Barker N: The upstream components of the Wnt signalling pathway in the dynamic EMT and MET associated with colorectal cancer progression. Clin Exp Metastasis 25: 657-663, 2008

9. Javle MM, Gibbs JF and Iwata KK: Epithelial-mesenchymal transition (EMT) and activated extracellular signal-regulated kinase (p-Erk) in surgically resected pancreatic cancer. Ann Surg Oncol 14: 3527-3533, 2007.

10. Yin T, Wang C, Liu T, Zhao G and Zhou F: Implication of EMT induced by TGF-beta1 in pancreatic cancer. J Huazhong Univ Sci Technolog Med Sci 26: 700-702, 2006.

11. Naithani R, Huma LC, Moriarty RM, McCormick DL and Mehta RG: Comprehensive review of cancer chemopreventive agents evaluated in experimental carcinogenesis models and clinical trials. Curr Med Chem 15: 1044-1071, 2008.

12. Verschoyle RD, Steward WP and Gescher AJ: Putative cancer chemopreventive agents of dietary origin - how safe are they? Nutr Cancer 59: 152-162, 2007.

13. Basnet $\mathrm{P}$ and Skalko-Basnet N: Curcumin: an anti-inflammatory molecule from a curry spice on the path to cancer treatment. Molecules 16: 4567-4598, 2011. 
14. Shehzad A, Wahid F and Lee YS: Curcumin in cancer chemoprevention: molecular targets, pharmacokinetics, bioavailability, and clinical trials. Arch Pharm 343: 489-499, 2010.

15. Jagtap S, Meganathan K, Wagh V, Winkler J, Hescheler J and Sachinidis A: Chemoprotective mechanism of the natural compounds, epigallocatechin-3-o-gallate, quercetin and curcumin against cancer and cardiovascular diseases. Curr Med Chem 16: 1451-1462, 2009.

16. Notarbartolo M, Poma P, Perri D, Dusonchet L, Cervello M and D'Alessandro N: Antitumor effects of curcumin, alone or in combination with cisplatin or doxorubicin, on human hepatic cancer cells. Cancer Lett 224: 53-65, 2005.

17. Chua HL, Bhat-Nakshatri P, Clare SE, Morimiya A, Badve S and Nakshatri H: NF-kappaB represses E-cadherin expression and enhances epithelial to mesenchymal transition of mammary epithelial cells: potential involvement of ZEB-1 and ZEB-2. Oncogene 26: 711-724, 2007.

18. Mulholland DJ, Kobayashi N and Ruscetti M: Pten loss and RAS/MAPK activation cooperate to promote EMT and metastasis initiated from prostate cancer stem/progenitor cells. Cancer Res 72: 1878-1889, 2012.

19. Chen MC, Chang WW, Kuan YD, Lin ST, Hsu HC and Lee CH: Resveratrol inhibits LPS-induced epithelial-mesenchymal transition in mouse melanoma model. Innate Immun 32: 1-9, 2012.

20. Takata M, Maniwa Y and Doi T: Double-layered collagen gel hemisphere for cell invasion assay: successful visualization and quantification of cell invasion activity. Cell Commun Adhes 14 157-167, 2007.

21. Tiwari N, Gheldof A, Tatari M and Christofori G: EMT as the ultimate survival mechanism of cancer cells. Semin Cancer Biol 22: 194-207, 2012.

22. Bachmeier BE, Mohrenz IV and Mirisola V: Curcumin downregulates the inflammatory cytokines CXCL1 and -2 in breast cancer cells via NFkappaB. Carcinogenesis 29: 779-789, 2008.

23. Kim HI, Huang H, Cheepala S, Huang S and Chung J: Curcumin inhibition of integrin (alpha6beta4)-dependent breast cancer cell motility and invasion. Cancer Prev Res (Phila) 1: 385-391, 2008
24. Lin SS, Lai KC, Hsu SC, et al: Curcumin inhibits the migration and invasion of human A549 lung cancer cells through the inhibition of matrix metalloproteinase-2 and -9 and vascular endothelial growth factor (VEGF). Cancer Lett 285: 127-133, 2009.

25. Dolcet X, Llobet D, Pallares J and Matias-Guiu X: NF- $\kappa B$ in development and progression of human cancer. Virchows Arch 446: 475-482, 2005

26. Giuliani C, Napolitano G, Bucci I, Montani V and Monaco F: $\mathrm{NF}-\kappa \mathrm{B}$ transcription factor: role in the pathogenesis of inflammatory, autoimmune, and neoplastic diseases and therapy implications. Clin Ter 152: 249-253, 2001 (In Italian).

27. Baud V and Jacque E: The alternative NF- $\kappa B$ activation pathway and cancer: friend or foe? Med Sci 24: 1083-1088, 2008 (In French).

28. Min C, Eddy SF, Sherr DH and Sonenshein GE: NF-kappaB and epithelial to mesenchymal transition of cancer. J Cell Biochem 104: 733-744, 2008.

29. Pinho SS, Oliveira $P$ and Cabral J: Loss and recovery of Mgat 3 and GnT-III mediated E-cadherin N-glycosylation is a mechanism involved in epithelial-mesenchymal transitions. PLoS One 7: e33191, 2012.

30. Ivaska J: Vimentin: Central hub in EMT induction? Small GTPases 2: 51-53, 2011.

31. Wu Y and Zhou BP: Snail: More than EMT. Cell Adh Migr 4: 199-203, 2010

32. Fendrich V, Waldmann $\mathrm{J}$ and Feldmann G: Unique expression pattern of the EMT markers Snail, Twist and E-cadherin in benign and malignant parathyroid neoplasia. Eur J Endocrinol 160: 695-703, 2009.

33. Shankar S, Nall D and Tang SN: Resveratrol inhibits pancreatic cancer stem cell characteristics in human and KrasG12D transgenic mice by inhibiting pluripotency maintaining factors and epithelial-mesenchymal transition. PLoS One 6: e16530, 2011.

34. Vergara D, Valente CM and Tinelli A: Resveratrol inhibits the epidermal growth factor-induced epithelial mesenchymal transition in MCF-7 cells. Cancer Lett 310: 1-8, 2011. 